\title{
The Management of Diabetic Foot Ulcers in Patients with SARS-CoV-2 during the COVID-19 Pandemic
}

\author{
Joseph Garvy L. Lai, MD, Paula Veronica S.J. Reyes, MD and Emmanuel P. Estrella, MD
}

Department of Orthopedics, College of Medicine, and Philippine General Hospital, University of the Philippines, Manila

\begin{abstract}
Objective. The COVID-19 pandemic continues to wreak havoc in all sectors of society one year after it was declared by the World Health Organization. This retrospective study aims to describe the clinical picture, management, and initial outcomes of patients with infected diabetic neuro-ischemic foot ulcerations (NIFU) afflicted with SARS-CoV-2 managed at a government tertiary hospital during the pandemic; and to compare those who survived from those who did not from this combination of diseases.
\end{abstract}

Methods. Chart review of patients with combined infected diabetic NIFU and COVID-19, admitted at the Philippine General Hospital serving as a COVID-19 referral center, from April 1 to December 31, 2020 was performed. Data collected included patient demographics, clinical presentation including NIFU grade and stage, and severity of COVID-19, coagulation and inflammatory laboratory results, management, and initial outcomes.

Results. A total of 59 patients with diabetic foot ulcer were co-managed by the Department of Orthopedics during this period of the pandemic. Nine of these patients were COVID-19 positive of which six patients did not survive their illness. The non-survivors were slightly older ( $58.33 \mathrm{vs.} 52.67 \mathrm{y} / \mathrm{o}$ ), had more co-morbidities, and presented with more severe COVID-19 (3 patients had critical COVID-19) than the survivors. All nine patients had deranged coagulation parameters including elevated D-dimer levels, and elevated inflammatory markers (CRP, Ferritin, LDH). Procalcitonin levels were increased in four of the non-survivors, and normal in all three survivors. Seven of the patients had severe (Grade II or III) and infected/ischemic (Stage B or D) NIFUs that required surgery; however, two patients succumbed to their illness prior to any surgery. Four of the six non-survivors died due to acute myocardial infarction.

Conclusion. The presence of NIFU and COVID-19 in a patient generally results in progression to a turbulent hospital course. This is due to the hypercoagulable and hyperinflammatory states that each disease entity produces, which when combined, are exacerbated. Levels of $\mathrm{D}$-dimer and inflammatory markers, especially procalcitonin, may be used as a predictor of poor outcome, even mortality, in this group of patients.

Keywords: COVID-19, SARS-CoV-2, diabetes mellitus, neuro-ischemic foot ulcer, NIFU

\section{INTRODUCTION}

Corresponding author: Joseph Garvy L. Lai, MD Department of Orthopedics College of Medicine Philippine General Hospital University of the Philippines Manila Taft Avenue, Ermita, Manila 1000, Philippines Email: jllai@up.edu.ph
The year 2019 was an ominous year that portended a mysterious disease, which has continued to devastate the whole world as of this writing. At the tail end of 2019, numerous severe pneumonias, then of unknown origin, were detected in the city of Wuhan, province of Hubei in China. This illness eventually termed COVID-19 was due to a novel beta-coronavirus, known as severe acute respiratory syndrome coronavirus 2 (SARS-CoV-2). This virus spread rapidly all over the world in the succeeding months prompting the World Health Organization (WHO) to declare COVID-19 a pandemic on March 11, 2020. By December 31, 2020, as reported in BBC News and sourced from the Johns Hopkins 
University, European Centre for Disease Prevention and Control, other national public health agencies, and the UN data on population, the confirmed cases of COVID-19 have almost reached 82.8 million, with over 1.8 million deaths worldwide. ${ }^{1}$ The severity of COVID-19 is quite diverse in presentation. Majority of those infected will only have mild self-limiting flu-like illness; while around $5 \%$ of cases, may progress to a severe fulminant pneumonia, acute respiratory distress syndrome (ARDS), multiple organ failure, septic shock or even death. The spread of this disease is mainly through large respiratory droplets; however, airborne, and other routes of transmissions cannot be ruled at this time.,3 New strains of the SARS-CoV-2 have also been reported which have triggered the surges in cases experienced all over the world. ${ }^{1}$

Individuals with diabetes mellitus have always been at higher risk of contracting acute infections with poorer prognosis due to suppression of their innate and humoral immune functions. Patients with uncontrolled diabetes for prolonged periods are at an increased risk of hospitalization due to severe bacterial pneumonia. During the recent past viral pandemics such as severe acute respiratory syndrome (SARS-CoV-1), influenza A (H1N1), and Middle East respiratory syndrome coronavirus (MERS-CoV), diabetes was also associated with increased hospitalizations and intensive care unit admissions, more severe viral infections, and increased mortality rates. ${ }^{4}$

A summary report from the Chinese Center for Disease Control and Prevention released just before the WHO declared COVID-19 a pandemic, showed that among over 44,000 confirmed cases of COVID-19, the case fatality rate (CFR) was 2.3\%. However, this CFR increased 3 to 5 times more in patients afflicted with co-morbidities such as cerebrovascular disease, diabetes mellitus, and hypertension. ${ }^{5}$ Factoring out other co-morbidities except diabetes, Guo et al. noted that diabetic patients are at higher risk of severe pneumonia, release of tissue injury-related enzymes, excessive uncontrolled inflammation responses (cytokine storm) and hypercoagulable state; all of which could lead to rapid deterioration and poorer prognosis of COVID-19. ${ }^{6}$ Another study out of China by Yan et al. echoed similar sentiments as Guo regarding severe inflammation responses of diabetics with COVID-19. However, Yan also found out that these cohort of patients were older, more likely to need mechanical ventilation and ICU admissions, and had higher mortality rates. ${ }^{7}$ In a systematic review, metaanalysis, and meta-regression of 6452 patients from 30 studies, Huang et al. associated diabetes mellitus with a more severe and progressive COVID-19 that may lead to ARDS and even death. ${ }^{8}$

Diabetes-related foot complications, which affect 15\% of patients with diabetes, are the most frequent precursor of lower extremity amputations. Diabetic neuropathy and peripheral vascular disease acting alone, together, or in combination with biomechanical abnormalities, microvascular disease, increased susceptibility to infection, and limited joint mobility, are considered the main etiologies in the formation of diabetic neuro-ischemic foot ulcerations (NIFU). ${ }^{9,10}$ Since both diabetic foot ulcers and COVID-19 create cytokine and inflammation perturbations, Papanas and Papachristous (2020) posed the question regarding the possible bidirectional relationship between the two diseases: "Which might aggravate which?"11 In a recent article, Boulton noted that the risk factors for mortality in patients with diabetes admitted for COVID-19 (i.e., elderly, male with poor glycemic control, hypertension and cardiovascular disease) were the same risk factors for people with diabetes who develop foot complications. ${ }^{12}$ On the other hand, Atri et al. proposed several pathogenetic links between diabetic foot ulcers and COVID-19. This included the chronic low-grade inflammation and the hypercoagulable states that may lead to peripheral arterial disease, which are seen in both diabetics and COVID-19 afflicted patients, that may, in turn, have the propensity to develop a more severe diabetic foot complication. ${ }^{13}$

Recently the International Working Group on the Diabetic Foot (IWGDF) has updated its guidelines on the diagnosis and treatment of foot infection in persons with diabetes. ${ }^{14}$ However the chaos created by the COVID-19 pandemic on the healthcare system has made compliance with these guidelines quite difficult. Out-of-the-box solutions such as telemedicine, remote patient monitoring, home visits and outpatient surgical centers were emphasized to minimize unnecessary exposure of high-risk diabetic patients to SARS-CoV-2. However, diabetic patients presenting with infected NIFU, in sepsis, or with other diabetic complications will still require hospitalization. ${ }^{14,15}$

In the Philippines, by the end of 2020, the reported confirmed COVID-19 cases have gone past 472,000 with over 9200 deaths (death rate of 8.7). ${ }^{1}$ As a response to this pandemic, the Philippine government imposed a nationwide lockdown which restricted movement of the populace during the early months of the pandemic. Up to the present time, some form of quarantine is still imposed on major regions in the country. To address this health menace, the Department of Health designated the Philippine General Hospital (PGH), a tertiary and National University Hospital, as a COVID-19 referral center last April 2020. Hospital-wide changes in its operational procedures and infrastructure were instituted and geared toward the management of suspected and confirmed COVID-19 patients. At the same time, they aimed to ensure the safety of its healthcare personnel and administrative staff. Guidelines in the management of these patients were formulated not only to treat the infection and minimize exposure to SARS-CoV-2, but also to implement rational use of scarce resources such as manpower, hospital facilities and equipment, and personal protective equipment (PPE). Patients with diabetes mellitus complicated with severe infected neuro-ischemic foot ulcers, suspected or confirmed to have COVID-19, were admitted at the 
PGH and co-managed by the Department of Orthopedics throughout the pandemic. Since there is still so much that is unknown with this novel coronavirus, the guidelines formulated by the PGH are in constant flux, being evaluated and modified regularly to address the ever-changing needs of this pandemic.

Upon review of literature, there is a dearth of data on the in-hospital management of patients with severe diabetic NIFU that are also afflicted with COVID-19. This retrospective study, therefore, aims to describe and compare the patient demographics, clinical and laboratory (coagulation and inflammatory) pictures, management, and initial outcomes of patients with severe diabetic foot ulcers, infected with SARS-CoV-2, who either survived or not, while admitted at the PGH serving as a COVID-19 referral center during the pandemic.

\section{PATIENTS AND METHODS}

We included all diabetic patients complicated with severe infected NIFU, confirmed to be COVID-19 positive via nasopharyngeal swab RT-PCR, admitted at the PGH, serving as a COVID-19 referral center from April 1 to December 31, 2020, and co-managed by the Department of Orthopedics. Patients with diabetes and foot ulcerations but tested negative for SARS-CoV-2 were excluded.

Ethics review and approval were obtained from the University of the Philippines Manila Research Ethics Board (UPMREB). Informed consent was not necessary since only chart review of the case records of the included patients were undertaken by the authors. Data collected included patient demographics, clinical characteristics including classification of the diabetic foot ulceration using the University of Texas Staging System for Diabetic Foot Ulcers ${ }^{16,17}$ (Table 1) and severity of COVID-19 according to the $\mathrm{WHO}^{18}$ (Table 2); results of coagulation (Protime, Partial Thromboplastin Time, $\mathrm{D}$-dimer) and inflammatory (C-reactive protein, Ferritin, Procalcitonin, Lactate Dehydrogenase) laboratory work-ups and imaging; medical and surgical managements; and initial treatment outcomes. Data collected from the patients were kept in compliance with the Data Privacy Act of 2012.

\section{RESULTS}

From April 1 to December 31, 2020, 59 patients with diabetic NIFU were managed at the PGH serving as a COVID referral center and referred to the Department of Orthopedics for co-management. Of these 59 patients, 9 (15\%) were confirmed positive for SARS-CoV-2 via nasopharyngeal swab RT-PCR. The average age of these 9 patients ( 5 men, 4 women) was 56.4 years (range of 42-70). They all had type II diabetes mellitus for several years and requiring insulin but with poor compliance. Both lower extremities were involved in two patients, the left foot in five, and the right foot in two. Duration of the diabetic foot
Table 1. The University of Texas Staging System for Diabetic Foot Ulcers ${ }^{16,17}$

\begin{tabular}{cllll} 
Stage & \multicolumn{1}{c}{ Grade 0 } & \multicolumn{1}{c}{ Grade I } & \multicolumn{1}{c}{ Grade II } & \multicolumn{1}{c}{ Grade III } \\
A & $\begin{array}{l}\text { Pre- or Post- } \\
\text { ulcerative } \\
\text { lesion, } \\
\text { completely } \\
\text { epithelialized }\end{array}$ & $\begin{array}{l}\text { Superficial ulcer } \\
\text { not involving } \\
\text { tendon, capsule } \\
\text { or bone }\end{array}$ & $\begin{array}{l}\text { Ulcer } \\
\text { penetrating } \\
\text { to tendon or } \\
\text { capsule }\end{array}$ & $\begin{array}{l}\text { Ulcer } \\
\text { penetrating } \\
\text { to bone or } \\
\text { joint }\end{array}$ \\
\hline B & Infection & Infection & Infection & Infection \\
\hline C & Ischemia & Ischemia & Ischemia & Ischemia \\
\hline D & $\begin{array}{l}\text { Infection and } \\
\text { Ischemia }\end{array}$ & $\begin{array}{l}\text { Infection and } \\
\text { Ischemia }\end{array}$ & $\begin{array}{l}\text { Infection and } \\
\text { Ischemia }\end{array}$ & $\begin{array}{l}\text { Infection and } \\
\text { Ischemia }\end{array}$ \\
\hline
\end{tabular}

Score: NIFU Grade Stage

Table 2. Severity of COVID-19 (WHO) ${ }^{18}$

\begin{tabular}{|c|c|}
\hline Severity & Description \\
\hline Mild & $\begin{array}{l}\text { - Mild clinical presentation } \\
\text { - Without evidence of viral pneumonia or hypoxia }\end{array}$ \\
\hline Moderate & $\begin{array}{l}\text { - Clinical signs of pneumonia (fever, cough, dyspnea, } \\
\text { tachypnea) } \\
\text { - No signs of severe pneumonia } \\
\text { - } \mathrm{SpO}_{2}>90 \% \text { on room air } \\
\end{array}$ \\
\hline Severe & $\begin{array}{l}\text { - Clinical signs of pneumonia (fever, cough, dyspnea, } \\
\text { tachypnea) } \\
\text { - Respiratory rate }>30 / \text { minute; oxygen saturation < } \\
90 \% \text { on room air; } \mathrm{PaO}_{2} / \mathrm{FiO}_{2}<300 \mathrm{mmHg} \\
\text { - Severe respiratory distress (accessory muscle use, } \\
\text { inability to complete full sentences) }\end{array}$ \\
\hline Critical & $\begin{array}{l}\text { - Requires life sustaining treatment (mechanical } \\
\text { ventilation) } \\
\text { - Acute Respiratory Distress Syndrome (ARDS); } \\
\text { Sepsis; Septic Shock; Multiple organ failure } \\
\text { - Requiring admission to intensive care unit (ICU) }\end{array}$ \\
\hline
\end{tabular}

ulceration(s) ranged from 4 days to 3 months. Using the University of Texas Staging System for Diabetic Foot Ulcers, $8(72.7 \%)$ out of the 11 involved lower limbs had ulcerations deep into the tendon or capsule (Grade II) or into the bone/ joint (Grade III), which were either infected (Stage B) or both infected and ischemic (Stage D). Four patients had previous NIFUs necessitating surgeries that were performed months to years prior their current admission at the PGH. All nine patients, except for one, presented with co-morbidities upon admission: hypertension, heart failure, dyslipidemia, chronic kidney disease, encephalopathy, cerebrovascular disease, pneumonia, pleural effusion, liver cirrhosis, chronic hepatitis B, acute gastroenteritis, anemia, multiple electrolyte imbalances, and sacral decubitus ulcer. Using the WHO criteria for the severity of COVID-19, three patients had critical COVID-19 requiring intubation and mechanical ventilatory support, two had severe COVID-19 on oxygen supplementation via face mask or nasal cannula, three had moderate COVID-19, while only one patient had mild COVID-19 (Table 3).

The coagulation laboratory work-up showed derangement in 8 out of the 9 patients with NIFU and COVID-19, 
Table 3. Summary of Patient Profile

\begin{tabular}{ll}
\multicolumn{1}{c}{ Clinical characteristic } & No. of patients \\
\hline Involvement & \\
Bilateral & 2 \\
Right & 2 \\
Left & 5 \\
\hline University of Texas Staging System for DFU & \\
IB & 2 \\
IC & 1 \\
IIB & 1 \\
IID & 3 \\
IIIB & 1 \\
IIID & 3 \\
\hline Co-morbidities & \\
Anemia & 4 \\
Chronic kidney disease & 4 \\
Hypertension & 3 \\
Pneumonia & 3 \\
Chronic hepatitis B & 2 \\
Encephalopathy & 2 \\
Multiple electrolyte imbalances & 2 \\
Acute gastroenteritis & 1 \\
Cerebrovascular disease & 1 \\
Dyslipidemia & 1 \\
Heart Failure & 1 \\
Liver cirrhosis & 1 \\
Pleural effusion & 1 \\
Sacral decubitus ulcer & 1 \\
\hline WHO Severity of COVID-19 & 3 \\
Mild & 3 \\
Moderate & 2 \\
Severe & \\
Critical & \\
\hline & \\
\hline &
\end{tabular}

DFU, Diabetic foot ulcer

exhibiting prolonged protime as compared to controls. Seven patients also had elevated D-dimer (N.V. $<0.5 \mathrm{mg} / \mathrm{L}$ ) ranging from $0.98-20 \mathrm{mg} / \mathrm{L}$, while in two patients the D-dimer was not determined. For inflammatory markers, all nine patients with severe NIFU and SARS-CoV-2 had elevated levels of ferritin (N.V. $=17.9-464 \mathrm{ng} / \mathrm{ml}$, range $=$ 634-1390 ng/ml), C-reactive protein (CRP) (N.V. = 1 - 3 $\mathrm{mg} / \mathrm{L}$, range $=6.27-300 \mathrm{mg} / \mathrm{L}$ ), and lactate dehydrogenase $(\mathrm{LDH})(\mathrm{N} . \mathrm{V} .=120-246 \mathrm{U} / \mathrm{L}$, range $=254-1566 \mathrm{U} / \mathrm{L})$. Another inflammatory marker, procalcitonin (PCT), on the other hand, was increased in four of the nine patients $($ N.V. $<0.25 \mathrm{ng} / \mathrm{ml}$, range $=0.90-12.94 \mathrm{ng} / \mathrm{ml})$. Three patients had normal PCT; while in two patients, PCT was not determined. All nine patients presented with pneumonia on chest radiographs upon admission.

Surgical procedures were performed on five patients with NIFU and COVID-19. Two patients underwent belowknee amputations, one had an above-knee amputation, and two had multiple procedures/surgeries performed on them due to the severity of their NIFUs. One had a below-knee amputation on the left leg, with a $1^{\text {st }}$ ray amputation and heel debridement of the right foot. Another patient underwent three debridement procedures of her left hip disarticulation stump prior to formal stump closure. Four patients did not undergo any surgical procedure while admitted at the PGH: two only required regular bedside dressing changes since their ulcers were superficial (University of Texas Staging System for DFU Grade I), while the other two patients succumbed to their illness prior to any surgical operation.

Medical management consisted of multiple intravenous antibiotics to cover for the polymicrobial nature of diabetic foot ulcers and bacterial pneumonia. All patients also required insulin for glycemic control. The presence of co-morbidities such as hypertension, chronic kidney or liver disease, gastritis, encephalopathy, were all treated accordingly. On the other hand, the anemia was corrected with the appropriate transfusions of blood products, while electrolyte imbalances were managed with the proper replacement therapies. The COVID-19 infection was managed with supportive treatment using dexamethasone, enoxaparin, acetylcysteine, vitamin $\mathrm{C}$ and zinc. Antivirals were used on a case-to-case basis. For severe to critical cases of COVID-19, oxygen supplementation was instituted. Four patients required ICU admissions; however only two were admitted into the ICU; one died before a vacancy opened; while another patient was taken out of diabetic ketoacidosis while awaiting ICU admission and was eventually admitted at the COVID ward.

For the initial treatment outcomes of these nine patients, only three of the COVID-19 positive patients with diabetic NIFU were alive after their admission, with an average hospital stay of 17.67 days (range, 14-20). The three survivors (two women and one man) had an average age of 52.67 years (range, 48-58). Two of them had grade II (Figure 1) or III stage D diabetic foot ulcers which required
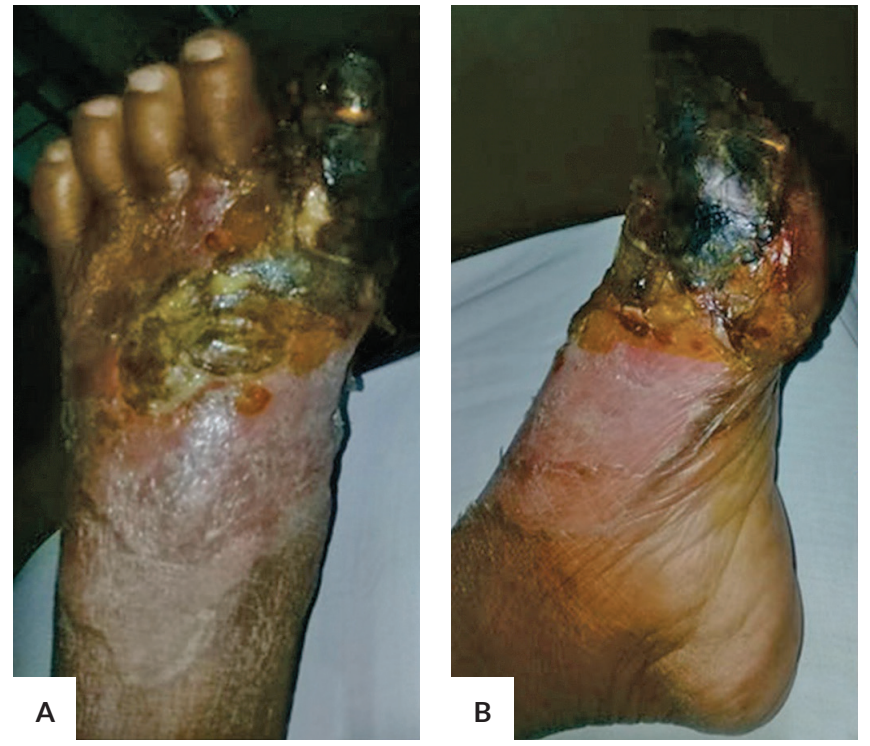

Figure 1. Left foot of a survivor with NIFU grade II stage D. Dorsal (A) and medial (B) aspects of the left foot showing wet gangrene of the $1^{\text {st }}$ toe with ulceration extending the dorsum of the forefoot and with note of purulent foul-smelling discharge. 

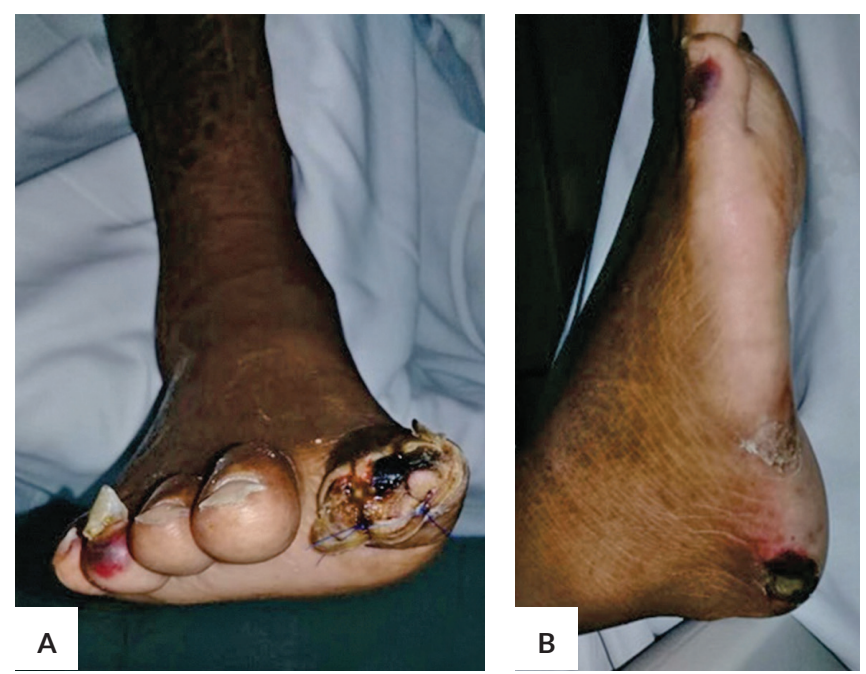

Figure 2. Right foot of a non-survivor with NIFU grade II stage $B$. (A) On end view showing dehiscence of $1^{\text {st }}$ toe disarticulation stump with necrotic tissue and purulent discharge. (B) Lateral view of the right foot showing pressure necrosis of lateral aspect of the right heel.

amputations (one below knee amputation and one above knee amputation), while the other one only had superficial grade I ulcers on both feet that only needed dressing changes. Two had moderate COVID-19, while the third had severe COVID-19 which required oxygen supplementation via face mask upon admission. All three survivors had elevated ferritin, CRP, LDH and D-dimer levels, but normal procalcitonin levels. Chest radiograph showed findings of pneumonia.

The other six patients who did not survive, lasted an average of 14 days (range, $4-34$ days) in the hospital. The average age of the non-survivors (four men and two women) was 58.33 years (range, 42-70). All six non-survivors except for one, had grade II (Figure 2) or III (Figure 3), and stage B (infected) or D (both infected and ischemic) NIFUs. Three of them underwent surgeries resulting in amputations of their lower limbs, with two undergoing multiple procedures in doing so. Two patients also required surgeries but died before any procedure was done, while another patient only needed dressing changes. Three of the non-survivors presented with critical COVID-19 requiring mechanical ventilatory support; while the other three either had severe, moderate, or mild COVID-19. All six non-survivors had deranged coagulation parameters; with 4 patients having increased $\mathrm{D}$-dimer levels (2 patients did not have a D-dimer determination). Inflammatory markers ferritin, CRP and $\mathrm{LDH}$ were all elevated in the non-survivors, while PCT was increased in four (2 patients did not have a PCT determination). The immediate cause of death in four patients was acute myocardial infarction, one died due to septic shock, while another died due to neurohypoglycopenia. (Table 4)
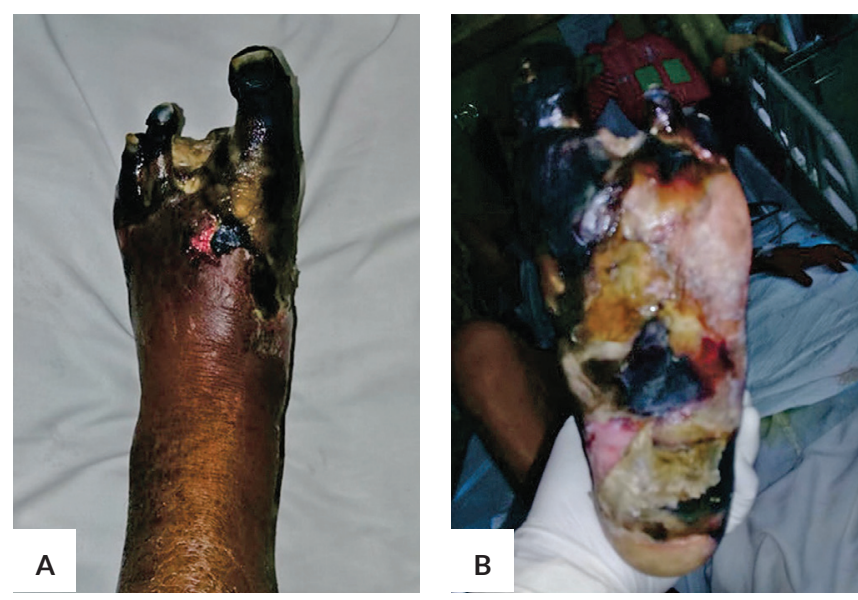

Figure 3. Left foot of a non-survivor with NIFU grade III stage D. (A) Dorsal aspect showing wet gangrene involving fore- to midfoot areas. (B) Plantar aspect showing wet gangrene of the entire $1^{\text {st }}$ ray and remaining toes, with areas of necrotic skin at the mid- and hindfoot areas. There is also note of absence of $2^{\text {nd }}$ and $3^{\text {rd }}$ toes with dehiscence and purulent discharge from the stump.

\section{DISCUSSION}

The scourge of the COVID-19 pandemic has persisted even after a year; and with the emergence of new strains of SARS-CoV-2, surges in the numbers of confirmed cases and fatalities are still being experienced around the globe. ${ }^{1}$ Its toll on the citizenry, including the healthcare workers, and the nation's economy is immeasurable such that the prevailing sentiments of the time are fear and despair. Despite this seemingly futile situation, the PGH, serving as a COVID-19 referral center, has been a beacon of hope. Through innovative strategies and rational utilization of its meager resources, with support from the government and private enterprises, the gates of the PGH have remained open for the country's indigent patients afflicted with SARS-CoV-2, a year after the onset of the pandemic.

Community quarantine was implemented during the pandemic to limit the spread of the virus, while at the same time, to allow the health sector to cope with this disease. This strategy of the government to restrict public movement and to encourage staying at home, may have limited the number of orthopedic cases caused by traumatic injuries such as motor vehicular accidents. However, these same restrictions also interrupted the preventive education, early treatment and diagnosis of patients afflicted with diabetes and diabetic foot ulcerations, as noted by Caruso et al. in Italy. This may, therefore, have lead to increased hospitalization of patients with more severe NIFU at higher amputation risk. ${ }^{19}$ Although lower in number compared to the prepandemic census, which may be due to the lockdowns that restricted mobility for fear of being exposed to COVID-19, 
Table 4. Comparative profile of survivors vs. non-survivors

\begin{tabular}{lcc} 
Age (Average, range) (yrs.) & $\begin{array}{c}\text { Survivors } \\
\mathbf{n}=3 \text { patients }\end{array}$ & $\begin{array}{c}\text { Non-survivors } \\
\mathbf{n}=\mathbf{6} \text { patients }\end{array}$ \\
\hline Men:Women & $1: 67(48-58)$ & $58.33(42-70)$ \\
\hline NIFU Grade/Stage (no. of limbs) & & $4: 2$ \\
IB & 2 & \\
IC & 0 & 0 \\
IIB & 0 & 1 \\
IID & 1 & 1 \\
IIIB & 0 & 2 \\
IIID & 1 & 1 \\
\hline
\end{tabular}

\begin{tabular}{|c|c|c|}
\hline \multicolumn{3}{|l|}{$\begin{array}{l}\text { Surgical Management } \\
\text { (no. of procedures) }\end{array}$} \\
\hline BKA & 1 & 2 \\
\hline AKA & 1 & 0 \\
\hline Ray amputation & 0 & 1 \\
\hline Debridement & 0 & 1 \\
\hline Change of dressing & 1 & 1 \\
\hline None & 0 & 2 \\
\hline \multicolumn{3}{|c|}{ WHO Severity of COVID-19 } \\
\hline Mild & 0 & 1 \\
\hline Moderate & 2 & 1 \\
\hline Severe & 1 & 1 \\
\hline Critical & 0 & 3 \\
\hline \multicolumn{3}{|l|}{ Laboratory work-up } \\
\hline Elevated ferritin & 3 & 6 \\
\hline Elevated CRP & 3 & 6 \\
\hline Elevated LDH & 3 & 6 \\
\hline Elevated D-dimer & - & 4 \\
\hline Elevated PCT & 0 & 4 \\
\hline $\begin{array}{l}\text { Chest } X \text {-ray findings } \\
\text { (no. of patients) }\end{array}$ & Pneumonia: 3 & Pneumonia: 6 \\
\hline $\begin{array}{l}\text { Length of hospital stay } \\
\text { (Ave, range) (days) }\end{array}$ & $17.67(14-20)$ & $14(4-34)$ \\
\hline Cause of death & 0 & $\begin{array}{c}\text { Myocardial } \\
\text { infarction: } 4 \\
\text { Septic shock: } 1 \\
\text { Neurohypo- } \\
\text { glycopenia: } 1\end{array}$ \\
\hline
\end{tabular}

BKA, Below-knee amputation; AKA, Above-knee amputation; CRP, $C$-reactive protein; $L D H$, Lactate dehydrogenase; $P C T$, Procalcitonin

patients with NIFU and more severe University of Texas grade and stage for DFUs were persistently referred to the Department of Orthopedics for co-management during the pandemic while other non- emergent orthopedic cases were markedly curtailed.

Diabetes mellitus suppresses the innate and humoral immune functions of an individual, placing them at higher risk for poorer outcomes during acute bacterial infections. During the past viral pandemics brought about by SARS$\mathrm{CoV}-1, \mathrm{H} 1 \mathrm{~N} 1$ and MERS-CoV, diabetes was also considered a risk factor for more severe viral infections that may result in increased hospitalizations, ICU admissions, and higher mortality rates. ${ }^{2-4}$ Besides patients with old age, cerebrovascular disease, cardiovascular disease and hypertension, patients with diabetes are more vulnerable to develop severe forms of COVID-19 pneumonia which may progress to acute respiratory distress syndrome, thereby necessitating mechanical ventilation and ICU admission, or other fatal complications such as multiple organ failure and/or septic shock. These dreadful outcomes are most likely due to the hyperinflammatory and hypercoagulable states each disease entity on its own produces in a patient, but are perilously exacerbated when diabetes mellitus and COVID-19 are combined. ${ }^{4,6-8}$ A summary report made by the Chinese Center for Disease Control and Prevention involving over 44,000 confirmed COVID-19 cases, showed a 3-5 times more increase in case fatality rate for diabetics with COVID-19 as compared to those without diabetes. ${ }^{5}$

Neuro-ischemic foot ulcers (NIFU) can complicate the course of diabetic patients in $15 \%$ of cases and are the most frequent harbinger for lower extremity amputations. NIFU will not only adversely affect the function of diabetics, but it may also cost their own lives if the ulcers become infected and progress to sepsis, given that they are more susceptible to infections and have deficient immune defense system. Since diabetic foot ulcers coupled with COVID-19 both create inflammation and cytokine system disruptions, Papanas and Papachristous (2020) posed the possible bidirectional relationship between the two disease entities and asked: "...which might aggravate which?"11 Atri proposed two pathogenetic links between diabetic foot ulcers and COVID-19. One is the inflammatory link, wherein diabetics, being in a generalized low-grade inflammatory state, have impaired wound healing that leads to chronic non-healing ulcers. Cytokine growth factors are believed to be involved in this process. On the other hand, complications of SARS-CoV-2 occur from an uncontrolled aberrant systemic inflammatory response or cytokine storm that leads to ARDS. Diabetic peripheral neuropathy and chronic foot ulcers are also noted to be influenced by abnormalities in cytokine levels. The second pathogenetic link is an ischemic link, wherein diabetic foot ulcers are produced by both peripheral arterial disease of the macrocirculation and neuroischemia due to impaired vasodilatation in the microcirculation. COVID-19, on the other hand, has been shown to induce coagulopathy with development of arterial and venous thrombi in the vascular bed and therefore, may also produce severe NIFUs. These hyperinflammatory and hypercoagulable states seen in either disease entity may aggravate the deleterious effects of the other leading to a more severe diabetic foot ulcer with more severe COVID-19 when both are combined in a patient. ${ }^{13}$

For the first nine months of the pandemic with the PGH serving as a COVID-19 referral center, nine (15.25\%) of 59 diabetic foot ulcer patients who were referred to the Department of Orthopedics for co-management, had COVID-19. Advanced age of these nine patients (average age, 56.4 years, range from 42-70), together with the presence of numerous co-morbidities such as hypertension, cardiovascular and cerebrovascular diseases besides diabetes, make this cohort of patients at higher risk to develop severe 
COVID-19 and may end up with a poorer outcome..$^{6-8}$ True enough, only one patient presented with mild COVID-19 upon admission, while there were three critical and two with severe COVID-19 in this group. Six (66.67\%) of the nine COVID-19 positive patients with diabetic foot ulcers did not survive their illness during their hospital stay. On the other hand, of the three patients who did survive, only one of them had severe COVID-19. Fortunately, all three of them recovered from COVID-19 and were discharged after a non-turbulent hospital stay.

Comparing their clinical profiles, the three COVID-19 positive patients with NIFU who survived were slightly younger (average age: 52.67 vs. 58.33 years), had less comorbidities, and less severe COVID-19 during their hospital stay than their non-survivor counterparts. Non-survivors had a slightly shorter hospital stay average (14 vs. 17.67 days) with two of them lasting only 4 days in the hospital. Three of the non-survivors contracted critical COVID-19 versus none in the survivor group. The more advanced age, presence of more concomitant illnesses, and more severe COVID-19 presentation of the non-survivors may have led to a more tumultuous hospitalization with a fatal outcome.

Both survivors and non-survivors had deranged coagulation parameters such as prolonged protime and partial thromboplastin time and increased levels of $\mathrm{D}$-dimer, which can be attributed to both their diabetic foot ulcers and COVID-19 illnesses. ${ }^{11-13} \mathrm{D}$-dimer represents the activation of the coagulation and fibrinolysis systems and a 3- to 4-fold increase in its levels in the early stages of COVID-19 may lead to a poor prognosis. ${ }^{20}$ Yao, in a case control study, also noted that $\mathrm{D}$-dimer levels significantly increased with increasing severity of COVID-19. Median D-dimer levels in non-survivors were significantly higher than in survivors of COVID-19, and that D-dimer level of $>2.14 \mathrm{mg} / \mathrm{L}$ predicted in-hospital mortality with sensitivity of $88.2 \%$ and specificity of $71.3 \% .{ }^{21}$ This hypercoagulable state may have induced acute myocardial infarction that caused the demise of four of the six non-survivors.

The inflammatory markers tested in this group of patients, namely $\mathrm{C}$-reactive protein, ferritin and lactic dehydrogenase, were all elevated. In a meta-analysis by Zeng et al., increased levels of CRP, ESR, ferritin, PCT, and serum amylase were all associated with more severe COVID-19. ${ }^{22}$ Elevated lactic dehydrogenase levels were associated with a 6-fold increased risk of developing severe disease and a 16-fold increase in odds of mortality in patients with COVID-19. ${ }^{23}$ In this study, however, procalcitonin may be a better predictor of mortality than the other inflammatory markers mentioned above since four of the six non-survivors had elevated PCT levels, while all three survivors had normal PCT levels. The PCT levels in two of the nonsurvivors were not determined. In a retrospective cohort study by $\mathrm{Hu}$, mean PCT levels were four times higher in severe than in moderate COVID-19 and were eight times higher in critical than in moderate patients. Hu also noted that for discharged patients, PCT levels decreased during recovery while for those who died of COVID-19, their PCT increased as the disease worsened. ${ }^{24}$ These findings by $\mathrm{Hu}$ approximates the PCT profile of the patients, both survivors and non-survivors, in this study.

Diabetic foot ulcers that are classified as grade II and III (penetrating to the tendon/capsule or bone/joint) with stage $\mathrm{B}$ (infected) or D (both infected and ischemic) which were mostly noted in our patients, all required some form of ablative surgery. Non-surgical management such as bedside change of dressings is only reserved for diabetic foot ulcerations that are superficial (Grade I) and non-infected (Stage A). For the two survivors that required surgery, their infected limbs only necessitated one amputation procedure each to control the infection. However, two of the six non-survivors underwent multiple surgeries after the initial amputation to finally control their infection. The severity of foot ulcerations dictated the type (amputation or debridement) and number of surgical procedures needed by each patient. The stresses brought about by the surgeries on a diabetic patient with COVID-19 may also contribute to their stormy hospital course and pernicious outcome.

This study is limited by its retrospective nature and small number of cases in a single center. Comparison between patients with diabetic foot ulcers who were COVID-19 positive to those who were not, will give a clearer picture as to their clinical and laboratory characteristics, proper management, and prognosis. Following up NIFU patients with SARS-CoV-2 for a longer period after being discharged would also give the physician a better understanding of the long-term effects of COVID-19 on diabetic patients with foot ulcers.

\section{CONCLUSION}

Diabetic neuroischemic foot ulcer patients compounded with COVID-19 generally progress to a more tempestuous hospital course due to the exacerbation of the hypercoagulable and hyperinflammatory states that each disease entity individually produces that when combined, worsens the course. Elevated levels of D-dimer and inflammatory markers, especially procalcitonin, may be used as predictors of poor outcomes including in-hospital mortality in this cohort of patients.

\section{Statement of Authorship}

All authors participated in the data collection and analysis and approved the final version of manuscript submitted.

\section{Author Disclosure}

All authors declared no conflicts of interest.

\section{Funding Source}

This paper was self-funded. 


\section{REFERENCES}

1. Coronavirus pandemic: tracking the global outbreak. [Internet]. 2021 [cited 2021 April]. Available from: www.bbc.com/news/ world-51235105

2. Gupta R, Ghosh A, Singh AL, Misra A. Clinical considerations for patients with diabetes in time of COVID-19 epidemic. Diabetes Metab Syndr. 2020; 14:211-2. doi: 10.1016/j.dsx.2020.03.002

3. Hussain A, Bhowmik B, do Vale Moreira NC. COVID-19 and diabetes: knowledge in progress. Diabetes Res Clin Pract. 2020; 162:108142. doi: 10.1016/j.diabres.2020.108142

4. Singh AK, Gupta R, Ghosh A, Misra A. Diabetes in COVID-19 pandemic: pathophysiology, prognosis and practical considerations. Diabetes Metab Syndr. 2020; 14:303-10. doi: 10.1016/j.dsx.2020. 04.004

5. Wu Z, McGoogan JM. Characteristics of and important lessons from the coronavirus disease 2019 (COVID-19) outbreak in China: A summary of a report of 72,314 cases from the Chinese Center for Disease Control and Prevention. JAMA. 2020: 323(13):1239-42. doi: 10.1001/jama.2020.2648

6. Guo W, Li M, Dong Y, Zhou H, Zhang Z, Tian C, et al. Diabetes is a risk factor for the progression and prognosis of COVID-19. Diabetes Metab Res Rev. 2020; e3319. doi: 10.1002/dmrr.3319

7. Yan YL, Yang Y, Wang F, Ren H, Zhang S, Shi, X, et al. Clinical characteristics and outcomes of patients with severe COVID-19 with diabetes. BMJ Open Diabetes Res Care. 2020: 8:e001343. doi: $10.1136 /$ bmjdrc. 2020.001343

8. Huang I, Lim MA, Pranata R. Diabetes mellitus is associated with increased mortality and severity of disease in COVID-19 pneumonia - A systematic review, meta-analysis, and meta-regression. Diabetes Metab Syndr. 2020; 14:395-403. doi: 10.1016/j.dsx.2020.04.018

9. Sinwar PD. The diabetic foot management - recent advance, Int J Surg. 2015; 15:27-30. doi: 10.1016/j.jijsu.2015.01.023

10. Lim JZM, Ng NSL, Thomas C. Prevention and treatment of diabetic foot ulcers. J R Soc Med. 2017; 110(3):104-9

11. Papanas N, Papachristous S. COVID-19 and diabetic foot: Will the lamp burn bright? Int J Low Extrem Wounds. 2020. doi: 10.1177/1534734620921382

12. Boulton AJM. Diabetic foot disease during the COVID-19 pandemic. Medicina 2021; 57:97. doi: 10.3390/medicina57020097

13. Atri A, Kocherlakota CM, Dasgupta R. Managing diabetic foot in times of COVID-19: time to put the best 'foot' forward. Int J Diabetes Dev Ctries 2020; 40(3):321-8.
14. Lipsy BA, Senneville E, Abbas ZG, Aragon-Sanchez J, Diggle M, Embil JM, et al. Guidelines on the diagnosis and treatment of foot infection in persons with diabetes (IWGDF 2019 update). Diabetes Metab Res Rev. 2020; 36(S1):e3280. doi: 10.1002/dmrr.3280

15. Rogers LC, Lavery LA, Joseph WS, Armstrong DG. All feet on deck - The role of podiatry during the COVID-19 pandemic. Preventing hospitalizations in an overburdened healthcare system, reducing amputation and death in people with diabetes. J Am Podiatr Med Assoc. 2020 Mar 25. doi: 10.7547/20-051

16. Lavery LA, Armstrong DG, Harkless LB. Classification of diabetic foot wounds. J Foot Ankle Surg. 1996; 35(6):528-31

17. Armstrong DG, Lavery LA, Harkless LB. Validation of a diabetic wound classification system. The contribution of depth, infection and ischemia to risk of amputation. Diabetes Care. 1998; 21(5):855-9.

18. COVID-19 Clinical Management: Living Guidance, [Internet] Jan. 25, 2021. [cited 2021 April]. Available from: WHO/2019-nCoV/ clinical/2021.1

19. Caruso P,Longo M, Signoriello S, Gicchino M,Malorino MI,Bellastella $\mathrm{G}$, et al. Diabetic foot problems during the Covid-19 pandemic in tertiary care center: The emergency among the emergencies. Diabetes Care. 2020; 43:e123-e124. doi: 10.2337/dc20-1347

20. Rostami M, Mansouritorghabeh H. D-dimer level in COVID-19 infection: a systematic review. Expert Rev Hematol. 2020; 13(11): 1265-75. doi: 10.1080/17474086.2020.1831383

21. Yao YM, Cao JT, Wang QQ, Shi QF, Liu K, Luo Z, et al. D-dimer as biomarker for disease severity and mortality in COVID-19 patients: a case control study. J Intensive Care. 2020; 8:49. doi: 10.1186/ s40560-020-00466- Z

22. Zeng FR, Huang YZ, Guo Y, Yin MZ, Chen X, Xiao L, et al. Association of inflammatory markers with the severity of COVID-19: a meta-analysis. Int J Infect Dis. 2020; 96:467-74. doi: 10.1016/j. ijid.2020.05.055

23. Henry BM, Aggarwal G, Wong J, Benoit S, Vikse J, Plebani M, et al. Lactate dehydrogenase levels predict coronavirus disease 2019 (COVID-19) severity and mortality: a pooled analysis. Am J Emerg Med. 2020; 38:1722-6. doi: 10.1016/j.ajem.2020.05.073

24. Hu R, Han CF, Pei SY, Yin MZ, Chen X. Procalcitonin levels in COVID-19 patients. Int J Antimicrob Agents 2020; 56:106051. doi: 10.1016/j.ijantimicag.2020.106051 